\title{
Maximum static inspiratory and expiratory pressures with different
} lung volumes

\author{
Christopher G Lausted ${ }^{1}$, Arthur T Johnson*2, William H Scott², \\ Monique M Johnson ${ }^{3}$, Karen M Coyne ${ }^{4}$ and Derya C Coursey ${ }^{2}$
}

Address: ${ }^{1}$ The Institute for Systems Biology, 1441 North 34th Street, Seattle, WA 98103, USA, ${ }^{2}$ Biological Resources Engineering, University of Maryland, College Park, MD 20742, USA, ${ }^{3}$ GE Healthcare Technologies, 3114 N. Grandview Blvd W-553, Waukesha, WI 53188, USA and ${ }^{4}$ U.S. Army Edgewood CB Center, APG, MD 21010, USA

Email: Christopher G Lausted - clausted@systemsbiology.org; Arthur T Johnson* - artjohns@umd.edu; William H Scott - enduranc@umd.edu; Monique M Johnson - monique.marquardt@med.ge.com; Karen M Coyne - karen.coyne@us.army.mil; Derya C Coursey - derya@mail.umd.edu

* Corresponding author

Published: 05 May 2006

BioMedical Engineering OnLine 2006, 5:29 doi:10.1 186/1475-925X-5-29
Received: 18 November 2005

Accepted: 05 May 2006

This article is available from: http://www.biomedical-engineering-online.com/content/5/1/29

(C) 2006 Lausted et al; licensee BioMed Central Ltd.

This is an Open Access article distributed under the terms of the Creative Commons Attribution License (http://creativecommons.org/licenses/by/2.0), which permits unrestricted use, distribution, and reproduction in any medium, provided the original work is properly cited.

\begin{abstract}
Background: Maximum pressures developed by the respiratory muscles can indicate the health of the respiratory system, help to determine maximum respiratory flow rates, and contribute to respiratory power development. Past measurements of maximum pressures have been found to be inadequate for inclusion in some exercise models involving respiration.
\end{abstract}

Methods: Maximum inspiratory and expiratory airway pressures were measured over a range of lung volumes in 29 female and 19 male adults. A commercial bell spirometry system was programmed to occlude airflow at nine target lung volumes ranging from $10 \%$ to $90 \%$ of vital capacity.

Results: In women, maximum expiratory pressure increased with volume from 39 to $6 \mathrm{I} \mathrm{cmH} \mathrm{H}_{2} \mathrm{O}$ and maximum inspiratory pressure decreased with volume from 66 to $28 \mathrm{cmH}_{2} \mathrm{O}$. In men, maximum expiratory pressure increased with volume from 63 to $97 \mathrm{cmH}_{2} \mathrm{O}$ and maximum inspiratory pressure decreased with volume from 97 to $39 \mathrm{cmH}_{2} \mathrm{O}$. Equations describing pressures for both sexes are:

$$
\begin{aligned}
& P_{\mathrm{e}} / P_{\max }=0.1426 \operatorname{Ln}(\% \mathrm{VC})+0.3402 R^{2}=0.95 \\
& P_{i} / P_{\max }=0.234 \operatorname{Ln}(100-\% V C)-0.0828 R^{2}=0.96
\end{aligned}
$$

Conclusion: These results were found to be consistent with values and trends obtained by other authors. Regression equations may be suitable for respiratory mechanics models.

\section{Background}

While maximum respiratory pressures at the mouth have been measured in numerous subjects, less data exists to characterize maximum pressures as they vary with lung volume. Maximum pressure is volume dependent because muscle tension is length dependent, because muscle tension produces higher pressure with a smaller radius of curvature, and because respiratory tissue is elastic. Rahn et al. [1] first produced static pressure-volume diagrams from a group of adult men, and later, Cook et al. [2] produced 
pressure-volume diagrams from a larger group of subjects including women and children. These diagrams were useful in modeling the energetics of respiration [3] and in monitoring the progress of respiratory muscle training [4]. Yet the total number of subjects tested remained small, particularly regarding females. The present paper provides additional static pressure-volume data obtained from adult volunteers, both women and men.

\section{Methods \\ Subjects}

Forty-eight normal subjects agreed to participate in the study. The subjects were recruited from students and staff at the University of Maryland. The study was approved by the Institutional Review Board and all subjects gave informed consent. The subjects' characteristics are shown in Table 1.

\section{Protocol}

Subjects were first acquainted with the spirometer and the test protocol. They were instructed in the definition of functional residual capacity (FRC) as the resting volume of the lung and given time to practice finding FRC. The subjects were then measured for inspiratory capacity (IC) and expiratory reserve volume (ERV) relative to FRC. Volume measurements were repeated until three consecutive maneuvers produced volumes within a $100 \mathrm{ml}$ range. The average of the three volumes was recorded. Vital capacity (VC) was calculated as the sum of IC and ERV.

Maximum pressure measurements were taken from occlusions occurring at nine predetermined target volumes. The volumes were randomly ordered and ranged from $10 \%$ to $90 \%$ of VC by $10 \%$ increments. Subjects began each maneuver at FRC. Subjects were instructed to inhale or exhale, as necessary, to the desired volume. When the target volume was obtained, the occlusion valve automatically closed. The subject was told to inhale or exhale, as necessary, for two seconds. After two seconds of effort, the valve was released. This gave the subject access to fresh air for at least one minute of rest. More time was given, if desired. After all 18 measurements were taken, the test was repeated. The stronger effort, or higher maximum pressure, at each measurement was saved.

\section{Measurements}

A commercial spirometery system (Collins $^{\mathrm{TM}}$, Braintree, MA) was used for all the measurements. Lung volumes were monitored by the dry-seal bell spirometer. The occlusion valve and pressure transducer utilized were those located in what Collins refers to as its "universal breathing valve." Collins "Research Assistant" (RA) software controlled the occlusion valve and collected pressure and volume measurements. For the experiment, a supervisory program, "PV", was authored in Microsoft Visual Basic for Applications $^{\mathrm{TM}}$ to configure RA and provide feedback to the experimenters. PV was designed to fill the spirometer with an appropriate volume of fresh air prior to each measurement. It then calculated the spirometer volume corresponding to the target lung volume, taking thermal expansion into account. Occlusion was triggered automatically when the subject reached the target lung volume. As target lung volumes were randomly ordered, a randomization feature was built into PV. After each occlusion, RA returned pressure and volume data, which PV analyzed and saved to disk. The spirometer was calibrated each test day with a three-liter syringe and the pressure transducer was calibrated each day with a $10 \mathrm{cmH}_{2} \mathrm{O}$ manometer.

\section{Data analysis}

The maximum inhalation or exhalation pressure magnitude $\left(\mathrm{P}_{\mathrm{i}}\right.$ or $\left.\mathrm{P}_{\mathrm{e}}\right)$ at each lung volume $\left(\mathrm{V}_{\mathrm{L}}\right)$ was recorded by the computer. The average pressure for the last one second of each effort was calculated. This pressure was then used to correct $\mathrm{V}_{\mathrm{L}}$ using the method by Cook et al. [2]. Absolute lung volumes were not measured and volumes were calculated based on the assumption that residual volume was $26 \%$ that of TLC.

\section{Results}

Average maximum pressure values for all of the female subjects tested appear in Table 2 and values for all of the male subjects appear in Table 3. Observations were grouped according to the lung volumes at which occlusion occurred and actual volumes within each group were averaged to produce the tabled values. The pressures produced by the men were typically $64 \%$ higher than the women in expiration, and 53\% higher in inspiration.

Data were then scrutinized in an exploratory manner to see if they could be easily and universally fit by a simple mathematical expression [5]. It was found that both

Table I: Age, height, weight, and lung volume data in the two groups tested shown with standard deviations.

\begin{tabular}{cccccc}
\hline Group & Number of Subjects & Average Age (Range) & Average Height, cm & $\begin{array}{c}\text { Average Mass kg } \\
\text { Average Vital } \\
\text { Capacity, } L\end{array}$ \\
\hline Females & 29 & $25.5 \pm 3.7(18$ to 31$)$ & $164 \pm 6$ & $60.5 \pm 13.3$ & $3.58 \pm 0.63$ \\
Males & 19 & $26.5 \pm 4.3(19$ to 34) & $177 \pm 7$ & $74.1 \pm 8.8$ & $4.72 \pm 8.4$ \\
\hline
\end{tabular}


Table 2: Maximal inspiratory and expiratory static pressures at different lung volumes for the female subjects.

\begin{tabular}{|c|c|c|c|c|c|}
\hline \multirow{2}{*}{$\begin{array}{c}\text { Expiratory } \\
\text { Volume (\%VC) }\end{array}$} & \multicolumn{2}{|c|}{ Pressure } & \multirow{2}{*}{$\begin{array}{c}\text { Inspiratory } \\
\text { Volume (\%VC) }\end{array}$} & \multicolumn{2}{|c|}{ Pressure } \\
\hline & $\begin{array}{l}\text { Positive Pressure } \\
\quad\left(\mathrm{cmH}_{2} \mathrm{O}\right)\end{array}$ & $\mathrm{P}_{\mathrm{e}} / \mathrm{P}_{\max }$ & & $\begin{array}{c}\text { Negative Pressure } \\
\left(\mathrm{cmH}_{2} \mathrm{O}\right)\end{array}$ & $\mathrm{P}_{\mathrm{i}} / \mathrm{P}_{\max }$ \\
\hline $8.9 \pm 0.7$ & $38.7 \pm 25.0$ & 0.5864 & $12.1 \pm 0.9$ & $65.9 \pm 31.6$ & 0.9985 \\
\hline $18.4 \pm 1.0$ & $44.2 \pm 25.9$ & 0.6697 & $22.5 \pm 1.3$ & $65.0 \pm 31.6$ & 0.9848 \\
\hline $27.6 \pm 1.3$ & $53.4 \pm 30.7$ & 0.8091 & $33.0 \pm 1.8$ & $59.6 \pm 32.0$ & 0.9030 \\
\hline $37.3 \pm 1.5$ & $53.7 \pm 28.8$ & 0.8136 & $43.3 \pm 2.0$ & $55.0 \pm 32.0$ & 0.8333 \\
\hline $46.8 \pm 1.9$ & $53.3 \pm 28.9$ & 0.8076 & $53.5 \pm 2.2$ & $53.0 \pm 32.9$ & 0.8030 \\
\hline $56.2 \pm 2.2$ & $55.4 \pm 29.6$ & 0.8394 & $63.8 \pm 2.6$ & $47.6 \pm 28.3$ & 0.7212 \\
\hline $65.7 \pm 2.6$ & $57.3 \pm 33.2$ & 0.8682 & $73.6 \pm 2.6$ & $42.3 \pm 28.6$ & 0.6409 \\
\hline $74.7 \pm 3.2$ & $61.7 \pm 38.5$ & 0.9398 & $83.1 \pm 2.7$ & $34.2 \pm 27.4$ & 0.5182 \\
\hline $84.4 \pm 3.2$ & $61.2 \pm 39.0$ & 0.9273 & $92.6 \pm 2.4$ & $28.0 \pm 29.0$ & 0.4242 \\
\hline
\end{tabular}

Volumes are expressed in percent of vital capacity at ambient pressure. All values are shown with standard deviations. $P_{\max }$ for females was determined to be $66 \mathrm{cmH}_{2} \mathrm{O}$.

men's and women's data could be described by an expression of the form:

$\mathrm{P}_{\mathrm{e}} / \mathrm{P}_{\max }=\mathrm{A} \operatorname{Ln}(\% \mathrm{VC})+\mathrm{B}$ for exhalation

and

$\mathrm{P}_{\mathrm{i}} / \mathrm{P}_{\max }=\mathrm{C} \operatorname{Ln}(100-\% \mathrm{VC})+\mathrm{D}$ for inhalation

Here, $\mathrm{P}_{\max }$ is the asymptotically maximum pressure that could be developed by the respiratory muscles at any lung volume and $\mathrm{P}_{\mathrm{i}}$ is the maximum inspiratory pressure that can be developed at specific lung volumes. The average value of $\mathrm{P}_{\max }$ found by determining the limit of the nonlinear P-V curve for the group of subjects was found to be $102 \mathrm{cmH}_{2} \mathrm{O}$ for males and $66 \mathrm{cmH}_{2} \mathrm{O}$ for females, and was found to be the same for both inhalation and exhalation directions. Least squares regression using Microsoft Excel yielded the following two equations:

$\mathrm{P}_{\mathrm{e}} / \mathrm{P}_{\max }=0.1426 \mathrm{Ln}(\% \mathrm{VC})+0.3402 \mathrm{R}^{2}=0.9549$ and

$\mathrm{P}_{\mathrm{i}} / \mathrm{P}_{\max }=0.234 \operatorname{Ln}(100 \%-\% \mathrm{VC})-0.0828 \mathrm{R}^{2}=0.9642$

These equations are graphed in Figure 1.

\section{Discussion}

Greater (more positive) expiratory pressures were developed at higher $V_{L^{\prime}}$ while greater (more negative) inspiratory pressures were developed at lower $\mathrm{V}_{\mathrm{L}}$. In women $\mathrm{P}_{\mathrm{e}}$ increased with volume from 39 to $61 \mathrm{cmH}_{2} \mathrm{O}$ and $\mathrm{P}_{\mathrm{i}}$ decreased with volume from 66 to $28 \mathrm{cmH}_{2} \mathrm{O}$. In men, $\mathrm{P}_{\mathrm{e}}$ increased with volume from 63 to $97 \mathrm{cmH}_{2} \mathrm{O}$ and $\mathrm{P}_{1}$ decreased with volume from 97 to $39 \mathrm{cmH}_{2} \mathrm{O}$. These trends occur primarily for two reasons. First, respiratory muscles work both with and against respiratory tissue elastance to produce pressure. Expiratory efforts are aided by tissue elastance (lung recoil effects) at high $\mathrm{V}_{\mathrm{L}}$ and inhibited at low $\mathrm{V}_{\mathrm{L}}$. Inspiratory efforts are inhibited by tissue elastance at high $\mathrm{V}_{\mathrm{L}}$ and aided at low $\mathrm{V}_{\mathrm{L}}$. Second, respiratory muscles exert greater tension when they are

Table 3: Maximal inspiratory and expiratory static pressure at different lung volumes for the male subjects.

\begin{tabular}{|c|c|c|c|c|c|}
\hline \multirow{2}{*}{$\begin{array}{c}\text { Expiratory } \\
\text { Volume (\%VC) }\end{array}$} & \multicolumn{2}{|c|}{ Pressure } & \multirow{2}{*}{$\begin{array}{c}\text { Inspiratory } \\
\text { Volume (\%VC) }\end{array}$} & \multicolumn{2}{|c|}{ Pressure } \\
\hline & $\begin{array}{l}\text { Positive Pressure } \\
\qquad\left(\mathrm{cmH}_{2} \mathrm{O}\right)\end{array}$ & $\mathrm{P}_{\mathrm{e}} / \mathrm{P}_{\max }$ & & $\begin{array}{c}\text { Negative Pressure } \\
\left(\mathrm{cmH}_{2} \mathrm{O}\right)\end{array}$ & $\mathrm{P}_{\mathrm{i}} / \mathrm{P}_{\max }$ \\
\hline $8.2 \pm 1.0$ & $63.2 \pm 32.6$ & 0.6196 & $13.5 \pm 2.0$ & $96.7 \pm 45.5$ & 0.9480 \\
\hline $17.2 \pm 1.3$ & $75.3 \pm 39.0$ & 0.7382 & $24.2 \pm 2.8$ & $95.3 \pm 49.8$ & 0.9343 \\
\hline $26.2 \pm 1.6$ & $84.1 \pm 39.9$ & 0.8245 & $35.2 \pm 3.2$ & $97.3 \pm 52.2$ & 0.9539 \\
\hline $35.2 \pm 2.2$ & $91.6 \pm 38.3$ & 0.8980 & $45.9 \pm 3.6$ & $87.2 \pm 42.3$ & 0.8549 \\
\hline $44.8 \pm 2.6$ & $89.6 \pm 41.3$ & 0.8784 & $55.7 \pm 3.2$ & $77.9 \pm 36.9$ & 0.7637 \\
\hline $53.5 \pm 2.7$ & $93.3 \pm 36.3$ & 0.9147 & $66.7 \pm 4.2$ & $75.4 \pm 42.2$ & 0.7392 \\
\hline $62.6 \pm 3.4$ & $94.6 \pm 44.3$ & 0.9275 & $76.5 \pm 4.5$ & $69.4 \pm 40.4$ & 0.6804 \\
\hline $72.1 \pm 3.8$ & $94.2 \pm 43.3$ & 0.9235 & $85.5 \pm 4.9$ & $51.4 \pm 38.4$ & 0.5039 \\
\hline $80.8 \pm 4.2$ & $97.2 \pm 41.5$ & 0.9529 & $94.2 \pm 5.1$ & $38.9 \pm 38.8$ & 0.3814 \\
\hline
\end{tabular}

Volumes are expressed in percent of vital capacity at ambient pressure. All values are shown with standard deviations. $\mathrm{P}_{\text {max }}$ for males was determined to be $102 \mathrm{cmH}_{2} \mathrm{O}$. 


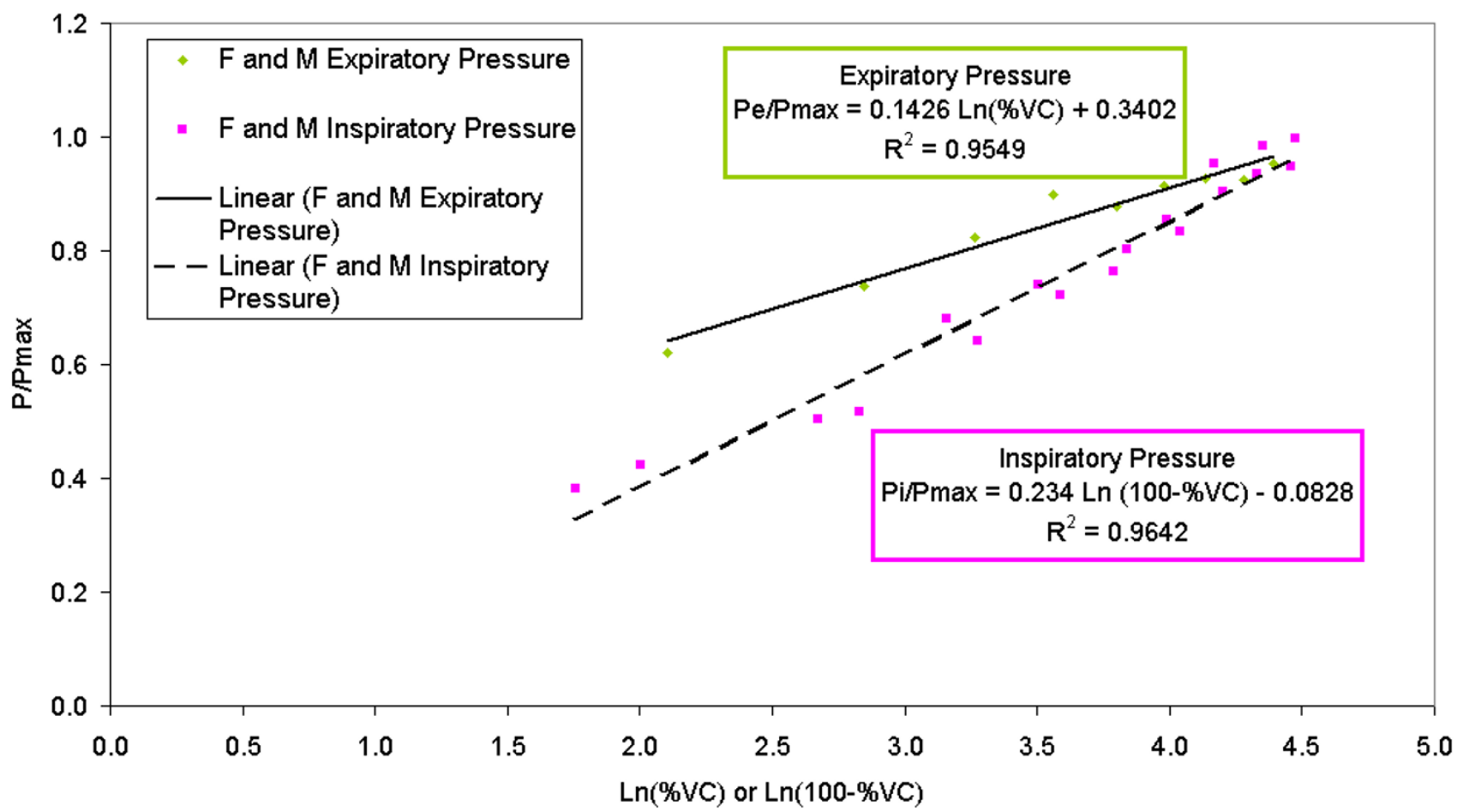

Figure I

Graph of empirical equations determined to describe relative expiratory and inspiratory pressures for men and women. Some data points are coincident. Symbols: $F=$ female; $M=$ male; other symbols as in text.

stretched to greater lengths. Expiratory muscles are stretched when the lung is inflated, while inspiratory muscles are stretched when the lung is deflated. Both of these factors describe the general trend of the data.

The volume dependence of $\mathrm{P}_{\mathrm{i}}$ was much more pronounced than the volume dependence of $\mathrm{P}_{\mathrm{e}}$ in both women and men. This can be seen as a higher slope of the inspiratory equation compared to the expiratory equation in Figure 1. This may reflect a combination of strength differences between diaphragm (largely responsible for inhalation) and abdominal muscles (largely responsible for exhalation) recruitment of intercoastal muscle (largely responsible for posture maintenance), and different mechanical advantages of each type of muscle as the lung volume varies.

The Laplace equation may be relevant here. This equation states that enclosed pressure is proportional to the product of wall tension and wall thickness and inversely proportional to the radius of curvature. The Laplace equation for a sphere differs from that of a cylinder by a factor of two. Pressure in a sphere $\left(\mathrm{P}=\frac{2 \tau \Delta r}{r}\right)$ is twice that of a cylinder $\left(\mathrm{P}=\frac{\tau \Delta r}{r}\right)$, all other things being equal.

The diaphragm is positioned under the lungs and curves upward in a somewhat spherical shape. As it contracts, it becomes flatter, meaning that its radius of curvature increases. Lung volume increases as the diaphragm contracts. If the Laplace equation can be applied to the respiratory system, then it would show that inspiratory pressure should decrease as radius, and thus lung volume, increases $\left(P_{i} \propto \frac{1}{V}\right.$, as long as wall tension and thickness remain steady).

The abdominal muscles are arranged differently, more like wrapping around a cylinder. The abdominal muscles flatten at smaller lung volumes instead of larger lung volumes, and the Laplace equation indicates that higher pressures should be developed at larger lung volumes $(\mathrm{P} \propto \mathrm{V})$. 
Both effects have been observed. Inspiratory pressures increase as lung volume decreases and expiratory pressure increases as lung volume increases. There is roughly a factor of two between the dependence of pressures upon lung volumes for inspiration and expiration. This could well be related to the difference in the Laplace equation for a sphere and a cylinder.

The pressure-volume data obtained in this study are of the same general magnitudes as those previously reported $[1,2,6]$. Rahn et al. [1] studied $P_{i}$ in 11 men and $P_{e}$ in 12 men using similar methods. The highest pressures from three efforts at each of six starting volumes were recorded. Measurements were read from a mercury manometer connected to the subjects' noses. Pressure-volume data closely match the results of the present study. Craig [6] produced pressure-volume diagrams from 10 men using methods similar to the present study. Pressures were taken from a mercury manometer connected to the subjects' mouths. These data also closely match the results of the present study. Cook et al. [2] studied 17 males and 9 females using two techniques. One technique was a conventional occlusion maneuver. The other technique involved subjects breathing into or out of large, fixed volumes. The compressibility of the air in differently sized containers provided for various ultimate lung volumes. The volumes were calculated from Boyle's Law using peak pressures that could be sustained for 1-2 seconds. Five volumes were used. It was concluded that the results of the occlusion method and the compression method were the same. In women, the compression-method $\mathrm{P}_{\mathrm{i}}$ values were similar to those of the present study at high volumes, but slightly higher at lower volumes. The $\mathrm{P}_{\mathrm{e}}$ values were similar at low volumes, but much higher at higher lung volumes. In men, the compression-method $P_{i}$ values agree well with those of the present study. However, the $\mathrm{P}_{\mathrm{e}}$ values are much higher than those of the present study at the higher volumes. Cook et al. [2] suggested that their $\mathrm{P}_{\mathrm{e}}$ values might have been higher than the Rahn et al. values because of the use of mouth pressure measurements rather than nose pressure measurements. It was also hypothesized that these $P_{e}$ values exceeded Craig's values due to better mouthpiece sealing.

As the results of this study are more in agreement with work of Rahn et al. [1] and Craig [6], it is more likely that there is another reason for the discrepancy. Aside from muscle strength alone, $\mathrm{P}_{\mathrm{e}}$ and $\mathrm{P}_{\mathrm{i}}$ are highly effort dependent. Subjects may limit their maximum pressures due to factors such as pain in the ear or general discomfort. During some maximum pressure maneuvers, researchers have observed changes in hemodynamics leading to loss of consciousness [7]. It is possible that the subjects of the Cook et al. [2] study were more highly motivated. It is also possible that these subjects were of above average strength.

Numerous authors have collected maximal pressures at a single $\mathrm{V}_{\mathrm{L}}$. Most recently, Wilson et al. [8] measured maximal $\mathrm{P}_{\mathrm{e}}$ and $\mathrm{P}_{\mathrm{i}}$ in 87 women and 48 men using partial occlusion and Bourdon gauges. The women were found to have $\mathrm{P}_{\mathrm{e}}=93 \pm 17 \mathrm{cmH}_{2} \mathrm{O}$ and $\mathrm{P}_{\mathrm{i}}=73 \pm 22 \mathrm{cmH}_{2} \mathrm{O}$ and the men were found to have $\mathrm{P}_{\mathrm{e}}=148 \pm 34 \mathrm{cmH}_{2} \mathrm{O}$ and $\mathrm{P}_{\mathrm{i}}=$ $106 \pm 31 \mathrm{cmH}_{2} \mathrm{O}$. It could be expected that the $\mathrm{P}_{\mathrm{i}}$ and $\mathrm{P}_{\mathrm{e}}$ values from a single volume study would exceed the values from a multiple volume study because more efforts are made at the optimal $\mathrm{V}_{\mathrm{L}}$ in the single volume study, while muscle fatigue can be a factor in the multiple volume study.

Judging from inspiration values, this does not appear to be the case. In the present study, women were found to have $\mathrm{P}_{\mathrm{i}}=66 \pm 32 \mathrm{cmH}_{2} \mathrm{O}$ at $\mathrm{V}_{\mathrm{L}}=12 \% \mathrm{VC}$ and men were found to have $P_{\mathrm{i}}=97 \pm 46 \mathrm{cmH}_{2} \mathrm{O}$ at $\mathrm{V}_{\mathrm{L}}=14 \% \mathrm{VC}$. These values are virtually identical to the Wilson et al. [8] data. On the other hand, women in this study were found to have $\mathrm{P}_{\mathrm{e}}=61 \pm 39 \mathrm{cmH}_{2} \mathrm{O}$ at $\mathrm{V}_{\mathrm{L}}=84 \% \mathrm{VC}$ and men were found to have $\mathrm{P}_{\mathrm{e}} 97 \pm 42 \mathrm{cmH}_{2} \mathrm{O}$ at $\mathrm{V}_{\mathrm{L}}=81 \% \mathrm{VC}$. These values are considerably smaller than the Wilson et al. data. The $\mathrm{P}_{\mathrm{e}}$ values of the single volume study fall in between the maximum $P_{e}$ values of the present study and the maximum $\mathrm{P}_{\mathrm{e}}$ values of the Cook et al. [2] study.

Satisfactorily describing maximum lung pressures with mathematical expressions can be helpful for respiratory mechanical modeling [3]. It is not likely that maximal pressures would be developed in young, healthy adults during quiet breathing. During exercise, and especially during expiratory flow limitation, however, maximum pressures may well be developed. For example, modeling the effects of respiratory masks during hard work could use these equations to calculate respiratory work rate. These equation forms are good because pressures and lung volumes both appear as relative rather than absolute values. That way, both men's and women's pressures could be determined with the same equations despite large differences in absolute pressures developed. Respiratory models for those conditions could well use the equations developed here.

Although we have no data to support the notion, it is possible, if their respiratory mechanics changed proportionally, that maximum pressures developed by patients with respiratory impairments could be described by the same equations as developed here. That is because these equations are in relative pressure and volume form. One would expect that $P_{\max }$ could be much lower in diseased patients, but $\mathrm{P} / \mathrm{P}_{\max }$ could be scaled the same. If this were so, then 
equations developed here could have more universal value.

\section{Conclusion}

Maximum pressures at the mouth have been determined to depend on lung volumes. Equations to describe these pressures have been developed, and these are in a form that may be useful for modeling and predictive purposes.

\section{Abbreviations}

ERV expiratory reserve volume of the lung, $\mathrm{L}$

FRC functional residual capacity of the lung, L

IC inspiratory capacity of the lung, L

$\mathrm{P}_{\mathrm{e}}$ volume-dependent maximum expiratory pressure, $\mathrm{cmH}_{2} \mathrm{O}$

$P_{i}$ volume-dependent maximum inspiratory pressure, $\mathrm{cmH}_{2} \mathrm{O}$

$\mathrm{P}_{\max }$ volume-independent maximum pressure, $\mathrm{cmH}_{2} \mathrm{O}$

PV name of supervisory computer program

RA proprietary data acquisition and analysis program from Collins

TLC total lung capacity, L

$\mathrm{V}_{\mathrm{L}}$ lung volume, LVC

VC vital capacity of the lung, $\mathrm{L}$

\section{Competing interests}

The author(s) declare that they have no competing interests.

\section{Authors' contributions}

CGL wrote software and procedures, and conducted many of the tests. ATJ suggested the experiment, wrote much of the paper, and determined the form of equations. WHS provided support, including planning, protocol, and supplies. MMJ assisted with planning and conducted many of the tests. KMC assisted with planning and conducted many of the tests. DCC provided data analysis support.

\section{Acknowledgements}

This study was supported by the University of Maryland.

\section{References}

I. Rahn HA, Otis AB, Chadwick LE, Fenn WO: The pressure-volume diagram of the thorax and lung. Amer J Physiol 1946, | 46: $161-178$.
2. Cook CD, Mead J, Orzalesi MM: Static volume-pressure characteristics of the respiratory system during maximal efforts. J Appl Physiol 1964, 19:1016-1022.

3. Johnson AT: How much work is expended for respiration. Front Med Biol Engr 1993, 5:256-297.

4. Tzelpix GE, Vega DL, Cohen ME, Dennis McCool : Lung volume specificity of inspiratory muscle training. J Appl Physiol 1994, 77:789-794.

5. Johnson AT: Multidimensional curve-fitting program for biological data. Comput Prog Biomed 1984, 18:59-64.

6. Craig AB: Maximal work of one breathing cycle. J Appl Physiol 1960, 15:1098-1100.

7. Milic-Emili J, Orzalesi MM, Cook CD, Turner JM: Respiratory thoraco-abdominal mechanics in man. I Appl Physiol 1964, 19:217-223.

8. Wilson SH, Cooke NT, Edwards RTH, Spiro SG: Predicted normal values for maximal respiratory pressures in caucasian adults and children. Thorax 1984, 39:535-538.
Publish with Biomed Central and every scientist can read your work free of charge

"BioMed Central will be the most significant development for disseminating the results of biomedical research in our lifetime. "

Sir Paul Nurse, Cancer Research UK

Your research papers will be:

- available free of charge to the entire biomedical community

- peer reviewed and published immediately upon acceptance

- cited in PubMed and archived on PubMed Central

- yours - you keep the copyright

Submit your manuscript here:

http://www.biomedcentral.com/info/publishing_adv.asp
BioMedcentral 